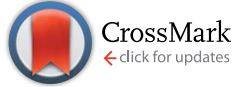

Cite this: RSC Adv., 2017, 7, 13232

Received 22nd November 2016 Accepted 13th February 2017

DOI: $10.1039 / c 6 r a 27176 f$

rsc.li/rsc-advances

\section{Photoinitiators for two-photon polymerisation: effect of branching and viscosity on polymerisation thresholds $\uparrow$}

\author{
Reece Whitby, ${ }^{\text {abdef }}$ Yael Ben-Tal, ${ }^{\text {bdef }}$ Ryan MacMillan, ${ }^{\text {def }}$ Stefaan Janssens, ${ }^{a}$ \\ Sebastiampillai Raymond, ${ }^{a}$ Dave Clarke, ${ }^{a}$ Jianyong Jin, ${ }^{\text {bf }}$ Andrew Kay ${ }^{* a e}$ \\ and M. Cather Simpson*bcdef
}

A series of multi-branched two-photon photoinitiators (PIs) based around the well-known triphenylamine donor core were synthesised for use in two-photon polymerisation (TPP) and are designated as compounds 6,7 and 8 . The use of a phenylene-vinylene $\pi$-system was used with an ethyl ester acceptor moiety which gives dipolar (6), quadrupolar (7) and octupolar (8) branching. Two-photon absorption cross-sections $\left(\delta_{2 \mathrm{PA}}\right)$ of $126 \mathrm{GM}, 358 \mathrm{GM}$ and $590 \mathrm{GM}$ were measured at $780 \mathrm{~nm}$ for 6, 7 and 8, respectively. The fluorescence quantum yields $\left(\phi_{\mathrm{F}}\right)$ were determined in both $\mathrm{MeOH}$ and the acrylate system employed for TPP, and demonstrate the impact of viscosity upon photophysical properties of multi-branched molecules. Excellent polymerisation thresholds were demonstrated in the $\mu \mathrm{W}$ region: namely $45 \mu \mathrm{W}(6), 61 \mu \mathrm{W}(7)$ and $27 \mu \mathrm{W}(8)$ at a writing speed of $50 \mu \mathrm{m} \mathrm{s}^{-1}$. Finally, an explanation for the disparity of polymerisation thresholds is proposed for these Pls and provides insight into the future development of low threshold PIs for TPP.

\section{Introduction}

The development of photoinitiators (PIs) for two-photon polymerisation (TPP) has been an area of intense research for nearly two decades. ${ }^{1-5}$ Many two-photon absorbing (2PA) materials have been developed in recent years to maximise 2PA cross-sections $\left(\delta_{2 \mathrm{PA}}\right)$, however often neglected are key factors that make them more useful for TPP. ${ }^{6-10}$ These include the need for low fluorescence quantum yields $\left(\phi_{\mathrm{F}}\right)$ and solubility in pre-polymer resins. Consequently, a large $\delta_{2 \mathrm{PA}}$ doesn't necessarily translate into an efficient PI. Many early 2PA materials possessed high $\delta_{2 \mathrm{PA}}$ but either exhibited large $\phi_{\mathrm{F}}$ yields or poor monomer solubility. ${ }^{3}$ Large $\phi_{\mathrm{F}}$ yields can lead to poor efficiency during TPP, as relaxation of the excited state via fluorescence and initiation from the triplet state are competing pathways. Therefore, minimising $\phi_{\mathrm{F}}$ yields is considered a key factor for maximising a PIs ability to function efficiently. ${ }^{11}$ The presence of carbonyl groups leads to

aPhotonics Team, Callaghan Innovation, Lower Hutt, New Zealand. E-mail: Andrew. Kay@callaghaninnovation.govt.nz

${ }^{b}$ School of Chemical Sciences, The University of Auckland, Auckland, New Zealand. E-mail: c.simpson@auckland.ac.nz; rwhi899@aucklanduni.ac.nz

${ }^{\circ}$ Department of Physics, The University of Auckland, Auckland, New Zealand

${ }^{d}$ The Photon Factory, The University of Auckland, Auckland, New Zealand

${ }^{e}$ The Dodd-Walls Centre for Photonic and Quantum Technologies, New Zealand

${ }^{f}$ The MacDiarmid Institute for Advanced Materials and Nanotechnology, New Zealand

$\dagger$ Electronic supplementary information (ESI) available: Further details of starting material synthesis (1-5), photophysical measurements, TPP and NMR data for final PIs 6-8. See DOI: 10.1039/c6ra27176f low-lying $\mathrm{n}-\pi^{*}$ excited states being present and this can result in a lowering of the $\phi_{\mathrm{F}}$ yields. ${ }^{12}$ For aromatic ketones, conjugation reduces the energy gap between singlet and triplet levels, leading to increased rate coefficients for intersystem crossing. ${ }^{\mathbf{1 3 , 1 4}}$ Carbonyl groups play a dual-role, as (1) strong electron acceptors and (2) efficient spin-orbit coupling agents to promote intersystem crossing. ${ }^{15-17}$ A number of research groups have utilised carbonyl moieties in the creation of 2PA PIs, with high sensitivity and low polymerisation thresholds..$^{2,3,11,17-21}$ These are often focussed on several well-known functional components, including; $\alpha$ - $\beta$-unsaturated ketones, ${ }^{3,16,21}$ thioxanthones, ${ }^{1,15}$ ketocoumarins, ${ }^{19,22}$ 1,3-diketones ${ }^{23}$ and acylo-phosphine oxides. ${ }^{24}$ Furthermore, many groups have produced dipolar, quadrupolar and octupolar PIs for TPP.,.$^{3,16,20,25,26}$ A number of groups have investigated the effects of branching on photophysical properties including, UV-Vis, fluorescence and on $\delta_{2 \mathrm{PA} \cdot} \cdot{ }^{27-30}$ However, to the best of our knowledge no data exist on how branching affects polymerisation thresholds. Many of these chromophores can be considered as twisted intramolecular charge-transfer (TICT) complexes and thus, their fluorescence properties are greatly influenced by local viscosity. ${ }^{31}$

Taking the above into account, we decided to utilise the strong electron donor triphenylamine for its propeller, $C_{3}$ symmetric shape that can be chemically modified for dipolar, quadrupolar and octupolar branching. ${ }^{\mathbf{1 0 , 3 2 , 3 3}}$ By modifying this donor core with ethyl ester functional groups to act as both an electron acceptor and to reduce $\phi_{\mathrm{F}}$ yields we believe these could be novel and viable materials. Consequently, we have designed 
and synthesised a series of branched $\mathrm{D}-[\pi-(\mathrm{C}=\mathrm{O})-\mathrm{R}]_{n}$ chromophores where $n=1,2,3$ viz. 6-8. Investigation of the photophysical properties of the PIs was conducted using UV-Vis, fluorescence, fluorescence lifetime and, z-scan measurements. Finally, TPP structuring tests conducted using a femtosecond laser system were performed at different intensities and writing speeds (irradiation times) to characterise the efficiency of these PIs for TPP.

\section{Experimental}

\subsection{Materials and characterisation}

Commercially available reagents were purchased from SigmaAldrich New Zealand, Pure Science Ltd, and SiliCycle Canada and were used without further purification. For our TPP tests we purchased commercially available monomers SR415 and SR315, these were purchased directly from Sartomer and used without further purification. Reagent and analytical grade solvents were used without further purification unless otherwise stated. Flash column chromatography was carried out using Silicycle SiliaFlash F60 silica (230-400 mesh) with the stated solvent systems. Analytical thin-layer chromatography (TLC) analyses were performed on pre-coated plates (Merck aluminium sheets, silica gel $60 \mathrm{~F} 254,0.2 \mathrm{~mm}$ ). Visualisation of chromophores was achieved by illumination under ultraviolet light (254 and $365 \mathrm{~nm}$ ). NMR were performed on a BRUKER-500 MHz - FT-NMR spectrometer. The chemical shifts $(\mathrm{s}=$ singlet, $\mathrm{bs}=$ broad singlet, $\mathrm{d}=$ doublet, $\mathrm{t}=$ triplet, $\mathrm{q}=$ quartet, $\mathrm{m}=$ multiplet) are stated in ppm using TMS as the internal standard. NMR solvents used were of $\geq 99.5 \%$ purity. High-resolution mass spectrometry was performed using a Waters Q-TOF Premier ${ }^{\mathrm{TM}}$ tandem mass spectrometer. Melting points were recorded with an EZ-Melt automated melting point apparatus and are uncorrected.

\subsection{Measurements}

The UV-Vis absorption spectra were recorded on PerkinElmer Lambda $1050 \mathrm{WB}$ UV/VIS/NIR spectrometer at a concentration of $1 \times 10^{-5} \mathrm{~mol} \mathrm{~L}^{-1}$. Fluorescence spectra were recorded on a Cary Eclipse fluorescence spectrometer at a concentration of $2 \times$ $10^{-6} \mathrm{M}$. The fluorescence quantum yields were measured using quinine bisulphate (QBS) in $(0.05 \mathrm{M})$ sulphuric acid $\left(\phi_{\mathrm{F}}=0.52\right)$ as a reference standard. ${ }^{34}$ Two-photon absorption measurements were performed using the z-scan method, using a Toptica femtosecond fibre laser with a pulse duration of $100 \mathrm{fs}$, a repetition rate of $80 \mathrm{MHz}$ and an operating wavelength of $780 \mathrm{~nm}$. The resulting optical intensity at the focal point was $4.8 \mathrm{GW} \mathrm{cm}^{-2}$, further experimental details are provided in the ESI. $\dagger$ Measurements were performed using a concentration of $2 \times 10^{-2} \mathrm{~mol} \mathrm{~L}^{-1}$ in $\mathrm{CHCl}_{3}$. Rhodamine $6 \mathrm{G}(0.5 \mathrm{M})$ in $\mathrm{MeOH}$ was used as a reference standard, a measured value of $33 \mathrm{GM}$ was obtained and this is consistent with previous literature reports. ${ }^{35}$ The fluorescence decay profiles were acquired using the time correlated single photon counting method exciting the fluorescence with $375 \mathrm{~nm}$ pulsed photodiode with a pulse duration of $\sim 100$ ps. Fluorescence decay times were determined by analysis of the decay profiles by iterative reconvolution method.

\subsection{Synthesis and characterisation}

The intermediates 1-5 were prepared using known literature procedures and details can be found in the ESI, Fig. S1 and S2. $\dagger$

(E)-Ethyl 4-(4-(diphenylamino)styryl)benzoate (6). To a solution of $t$-BuOK $(1.35 \mathrm{~g}, 12 \mathrm{mmol})$ in anhydrous THF $(20 \mathrm{~mL})$ was added ethyl 4-((diethoxyphosphoryl)methyl)benzoate (5) (3.35 g, $11.15 \mathrm{mmol}$ ) dropwise over $30 \mathrm{mins}$ at $0{ }^{\circ} \mathrm{C}$. The solution was then stirred for 30 mins while being kept below $5{ }^{\circ} \mathrm{C}$. 4-Formyltriphenylamine (1) $(2.53 \mathrm{~g}, 9.26 \mathrm{mmol})$ in THF (10 mL) was slowly added and the solution was allowed to reach r.t and stirred overnight. The solution was quenched with sat. $\mathrm{NH}_{4} \mathrm{Cl}$ $(25 \mathrm{~mL})$ and THF was removed in vacuo. The solution was extracted into DCM $(50 \mathrm{ml})$ and washed with aq. $\mathrm{NH}_{4} \mathrm{Cl}(3 \times 25$ $\mathrm{mL}$ ) and brine (50 mL). The organic layer was dried over $\mathrm{MgSO}_{4}$, filtered and dried in vacuo. The solids were loaded onto silica gel and purified via column chromatography $\left(10 \% \mathrm{CHCl}_{3}\right.$ : petroleum spirit $60-80{ }^{\circ} \mathrm{C}$ ) to give pure $(E)$-ethyl 4 -(4-(diphenylamino)styryl) benzoate (6) $300 \mathrm{mg}, 15 \%$ yield. $^{36}(E)$-ethyl 4-(4-(diphenylamino) styryl)benzoate (6): yellow solid, $R_{\mathrm{f}} 0.75$ (50\% DCM : petroleum spirit 60-80 ${ }^{\circ} \mathrm{C}$ ), mp 128-130 ${ }^{\circ} \mathrm{C}$ (lit. 120-122 ${ }^{\circ} \mathrm{C}$ ). ${ }^{36}{ }^{1} \mathrm{H}$ NMR $\left(\mathrm{CDCl}_{3}\right): \delta 8.00\left(\mathrm{~d}, J=8.25 \mathrm{~Hz}, A r-\mathrm{CO}_{2} \mathrm{Et}, 2 \mathrm{H}\right), 7.52(\mathrm{~d}, J=8.25 \mathrm{~Hz}$, Ar- $\left.\mathrm{CO}_{2} \mathrm{Et}, 2 \mathrm{H}\right), 7.44-7.41\left(\mathrm{~m}, \mathrm{Ph}_{2} \mathrm{~N}-\mathrm{Ar}, 2 \mathrm{H}\right), 7.28-7.24$ (m, $\mathrm{Ph}_{2}-\mathrm{NAr}$, $4 \mathrm{H}), 7.15(\mathrm{~d}, J=16.51 \mathrm{~Hz},-\mathrm{NPh}-\mathrm{CH}=\mathrm{CH}-, 1 \mathrm{H}), 7.13-7.10\left(\mathrm{~m}, P h_{2^{-}}\right.$ NAr, 4H), 7.06-7.03 (m, Ph-N-Ar-CH=CH, 4H), $7.00(\mathrm{~d}, J=$ $16.51 \mathrm{~Hz},-\mathrm{NPh}-\mathrm{CH}=\mathrm{CH}-, 1 \mathrm{H}), 4.38(\mathrm{q}, J=7.13 \mathrm{~Hz}, 2 \mathrm{H}), 1.40(\mathrm{t}, J$ $=7.13 \mathrm{~Hz}, 3 \mathrm{H}) .{ }^{13} \mathrm{C} \mathrm{NMR}\left(\mathrm{CDCl}_{3}\right): 166.46,147.97,147.43,142.11$, $130.71,129.98,129.34,128.90,127.68,126.01,125.79,124.73$, 123.29, 123.18, 60.86, 14.37. HREI-MS: calcd for $\mathrm{C}_{29} \mathrm{H}_{25} \mathrm{NO}_{2}$ 419.1885, found $\mathrm{m} / \mathrm{z}[\mathrm{M}] 419.1886(100 \%) ; \Delta=0.2 \mathrm{ppm}$.

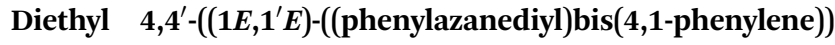
bis(ethene-2,1-diyl))dibenzoate (7). The synthesis of (7) was performed in the same manner as for (6), but using 4,4'-diformyltriphenylamine (2) (0.95 g, $3.16 \mathrm{mmol})$ as the starting material and with $2.27 \mathrm{~g}$, (7.57 mol) of (5). Following work up the crude solids were loaded onto silica gel and purified via column chromatography $\left(10 \% \mathrm{CHCl}_{3}\right.$ : petroleum spirit $60-80$ $\left.{ }^{\circ} \mathrm{C}\right)$ to give pure diethyl $4,4^{\prime}-\left(\left(1 E, 1^{\prime} E\right)\right.$-((phenylazanediyl)bis(4,1phenylene))bis(ethene-2,1-diyl))dibenzoate (7) $100 \mathrm{mg}, 5 \%$ yield. Diethyl $4,4^{\prime}-\left(\left(1 E, 1^{\prime} E\right)-((\right.$ phenylazanediyl $)$ bis(4,1-phenylene $\left.)\right)$ bis(ethene-2,1-diyl))dibenzoate (7): yellow solid, $R_{\mathrm{f}} 0.50(50 \%$ DCM : petroleum spirit $60-80{ }^{\circ} \mathrm{C}$ ), mp 109-111 ${ }^{\circ} \mathrm{C} .{ }^{1} \mathrm{H}$ NMR $\left(\mathrm{CDCl}_{3}\right): \delta 8.01\left(\mathrm{~d}, J=8.28 \mathrm{~Hz}, A r-\mathrm{CO}_{2} \mathrm{Et}, 4 \mathrm{H}\right), 7.54(\mathrm{~d}, J=8.28 \mathrm{~Hz}$, $\left.A r-\mathrm{CO}_{2} \mathrm{Et}, 4 \mathrm{H}\right), 7.44-7.41\left(\mathrm{~m}, J=8.37 \mathrm{~Hz}, \mathrm{Ph}_{2} \mathrm{~N}-A r, 4 \mathrm{H}\right), 7.30(\mathrm{t}$, $\left.P h-\mathrm{NAr}_{2}, 2 \mathrm{H}\right), 7.18-7.14(\mathrm{~m}, \mathrm{Ph}-\mathrm{N}-\mathrm{Ar}-\mathrm{CH}=\mathrm{CH}, 4 \mathrm{H}), 7.11-7.07(\mathrm{~m}$, Ph-N-Ar-CH=CH, 5H), $7.03(\mathrm{~d}, \mathrm{Ar}-\mathrm{CH}=\mathrm{CH}, 2 \mathrm{H}), 4.38(\mathrm{q}, J=$ $7.13 \mathrm{~Hz}, 4 \mathrm{H}), 1.40$ (t, $J=7.13 \mathrm{~Hz}, 6 \mathrm{H}) .{ }^{13} \mathrm{C} \mathrm{NMR}\left(\mathrm{CDCl}_{3}\right): 166.44$, $147.46,142.00,131.35$, 130.53, 130.00, 129.47, 129.00, 127.76, 126.16, 125.13, 123.84, 60.87, 14.36. HREI-MS: calcd for $\mathrm{C}_{40} \mathrm{H}_{35} \mathrm{NO}_{4}$ 593.2561, found $\mathrm{m} / \mathrm{z}[\mathrm{M}] 593.2566$ (90\%); $\Delta=$ $-0.8 \mathrm{ppm}$.

Triethyl 4, 4, $\mathbf{4}^{\prime \prime}-\left(\left(1 E, 1^{\prime} E, 1^{\prime \prime} E\right)\right.$-(nitrilotris(benzene-4,1-diyl)) tris(ethene-2,1-diyl))tribenzoate (8). The synthesis of (7) was performed in the same manner as for (6), but $4,4^{\prime}, 4^{\prime \prime}$-trisformyltriphenylamine (3) (0.37 g, $1.124 \mathrm{mmol})$ as the starting material and with $1.054 \mathrm{~g},(3.71 \mathrm{~mol})$ of (5). Following work up the crude solids were loaded onto silica gel and purified via 
column chromatography $\left(10 \% \mathrm{CHCl}_{3}\right.$ : petroleum spirit $60-80$ $\left.{ }^{\circ} \mathrm{C}\right)$ to yield pure triethyl $4,4^{\prime}, 4^{\prime \prime}-\left(\left(1 E, 1^{\prime} E, 1^{\prime \prime} E\right)\right.$-(nitrilotris(benzene4,1-diyl))tris(ethene-2,1-diyl))tribenzoate (8) $400 \mathrm{mg}, 46 \%$ yield. Triethyl $\quad 4,4^{\prime}, 4^{\prime \prime}-\left(\left(1 E, 1^{\prime} E, 1^{\prime \prime} E\right)\right.$-(nitrilotris(benzene-4,1-diyl))tris (ethene-2,1-diyl))tribenzoate (8): yellow solid, $R_{\mathrm{f}} \quad 0.50 \quad(50 \%$ DCM : petroleum spirit $60-80{ }^{\circ} \mathrm{C}$ ), mp 182-185 ${ }^{\circ} \mathrm{C} .{ }^{1} \mathrm{H}$ NMR $\left(\mathrm{CDCl}_{3}\right): \delta 8.02\left(\mathrm{~d}, J=8.24 \mathrm{~Hz}, A r-\mathrm{CO}_{2} \mathrm{Et}, 6 \mathrm{H}\right), 7.54(\mathrm{~d}, J=8.24 \mathrm{~Hz}$, $A r-\mathrm{CO}_{2} \mathrm{Et}, 6 \mathrm{H}$ ), 7.45 (d, $J=8.66 \mathrm{~Hz}, \mathrm{Ar}_{2} \mathrm{~N}-A r, 6 \mathrm{H}$ ), 7.18 (d, $J=$ 16.07 Hz, -NAr-CH=CH-, 3H), $7.13\left(\mathrm{~d}, J=8.66 \mathrm{~Hz}, \mathrm{Ar}_{2} \mathrm{~N}-\mathrm{Ar}, 6 \mathrm{H}\right)$, 7.05 (d, $J=16.07 \mathrm{~Hz},-\mathrm{NAr}-\mathrm{CH}=\mathrm{CH}-, 3 \mathrm{H}), 4.38$ (q, $J=7.10 \mathrm{~Hz}$, $6 \mathrm{H}), 1.41(\mathrm{t}, J=7.10 \mathrm{~Hz}, 9 \mathrm{H}) .{ }^{13} \mathrm{C} \mathrm{NMR}\left(\mathrm{CDCl}_{3}\right): 166.42,147.02$, 141.90, 131.89, 130.41, 130.01, 129.10, 127.85, 126.47, 126.10, 124.34, 60.89, 14.37. HREI-MS: calcd for $\mathrm{C}_{51} \mathrm{H}_{45} \mathrm{NO}_{6} 767.3347$, found $m / z[\mathrm{M}] 767.3248 ; \Delta=0.7 \mathrm{ppm}$.

\subsection{Two-photon polymerisation}

Laser system. A regeneratively amplified Ti:Sapphire femtosecond laser system (Mantis and Legend Elite, Coherent Inc., USA) operating at $800 \mathrm{~nm}$ with $110 \mathrm{fs}$ pulses and a Gaussian spatial profile was used to directly pattern 3D test structures. The system operates at $1000 \mathrm{~Hz}$, however the repetition rate was reduced for these experiments to $500 \mathrm{~Hz}$ using a pulse picker (Model 5046ER, FastPulse Technology Inc., USA). The average power (measured after the objective, just before the sample) required was less than $400 \mu \mathrm{W}$; variable average powers were obtained by reducing the laser output power using an Altechna ultraFAST Watt Pilot variable attenuator and neutral-density filters. The Gaussian beam was focused through an aspheric condenser lens with a 0.79 numerical aperture. A JPSA IX-100-C stage with minimum step size $0.1 \mu \mathrm{m}$ was used to position the sample with precise movements along the $X-Y-Z$ axes. A schematic of our setup is shown in Fig. S17. $\dagger$

General procedure. TPP structuring tests were performed using a 50:50 wt\% mixture of the commercial acrylates ethoxylated trimethylopropane triacrylate (SR415) and trimethylolpropane triacrylate (SR351) with a photoinitiator concentration of $6.3 \times 10^{-6} \mathrm{M}$. The same fabrication process was implemented for all structures: the optical material was dropcast onto a glass substrate and flattened to give a consistent thickness $(2 \mathrm{~mm})$. The laser beam was focussed inside the material and the focus was scanned across the material to create the desired pattern, a $150 \times 150$ cross-hatched square. The stage was then lowered $5 \mu \mathrm{m}$ in the $z$ direction to raise the focus within the material and the pattern was then written again. This process was repeated 10 times to ultimately give a 3D structure $50 \mu \mathrm{m}$ tall. Final structures were developed by washing with methanol and drying. Scanning electron microscopy (SEM) was employed to image the structures. The structures were sputter coated prior to SEM imaging ( $\sim 56 \mathrm{~nm})$.

\section{Results and discussion}

\subsection{Synthesis of triphenylamine photoinitiators 6-8}

The target compounds, 6-8, were synthesised via VilsmeierHaack formylation and Horner-Wadsworth-Emmons coupling as shown in Scheme 1.

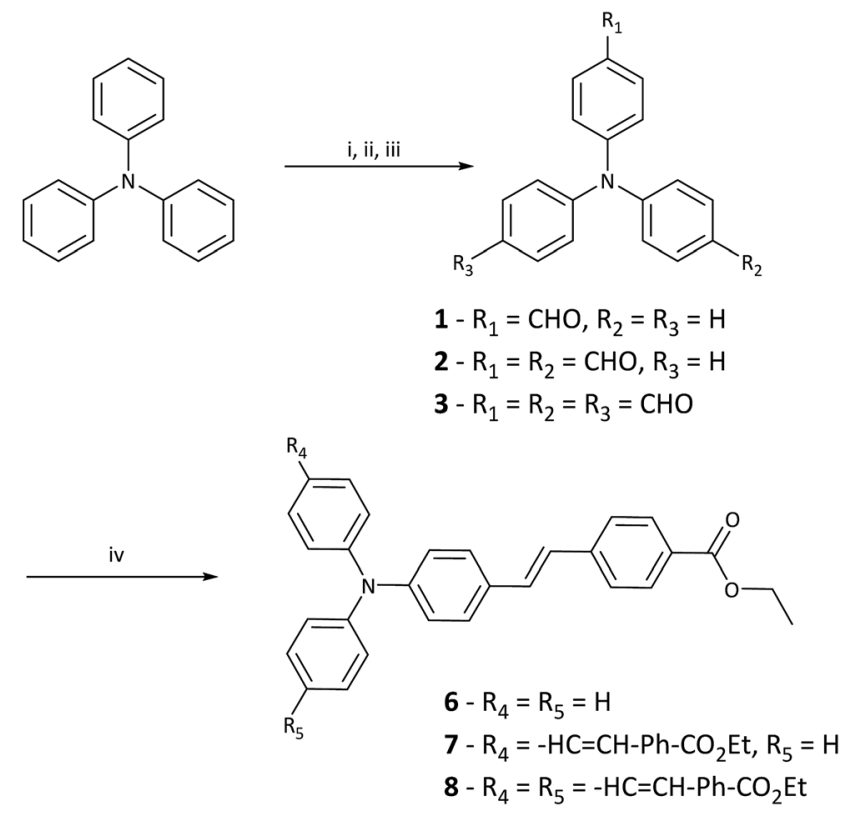

Scheme 1 Synthetic route for 1-3 and final PIs 6-8. Reagents and conditions: (i) DMF, $\mathrm{POCl}_{3}$ (1.05 eq.), $95^{\circ} \mathrm{C}$, overnight. (ii) $\mathrm{DMF}, \mathrm{POCl}_{3}$ (10.5 eq.), $95^{\circ} \mathrm{C}$, overnight. (iii) 1. DMF (23 eq.), $\mathrm{POCl}_{3}\left(25\right.$ eq.), $95^{\circ} \mathrm{C}$, overnight, aqueous workup and then 2. DMF (23 eq.), $\mathrm{POCl}_{3}$ (25 eq.), $95{ }^{\circ} \mathrm{C}$, overnight, aqueous workup. (iv). $t$-BuOK, THF, $0{ }^{\circ} \mathrm{C}>$ r.t., overnight.

4-Formyltriphenylamine (1) and 4,4'-diformyltriphenylamine (2) were prepared from triphenylamine via a VilsmeierHaack formylation according to the literature method. ${ }^{37} 4,4^{\prime}, 4^{\prime \prime}$ trisformyltriphenylamine (3) was prepared in two steps, also using a known procedure. ${ }^{38}$

Ethyl 4-methylbenzoate was converted into ethyl 4-(bromomethyl)benzoate (4) by radical bromination followed by treatment of 4 with triethyl phosphite to yield ethyl 4-((diethoxyphosphoryl) methyl)benzoate (5). ${ }^{39}$ The dipolar $(E)$-ethyl 4-(4-(diphenylamino) styryl)benzoate (6) was prepared by Horner-Wadsworth-Emmons coupling of 4-formyltriphenylamine (1) and ethyl 4-((diethoxyphosphoryl)methyl)benzoate (5) under standard conditions. The synthesis of 7 and $\mathbf{8}$ was conducted in the same manner as described for $\mathbf{6}$.

\subsection{Linear optical properties}

The normalised one-photon absorption and fluorescence spectra of 6-8 in $\mathrm{MeOH}$ are shown in Fig. 1 and results outlined in Table 1. Full experimental findings are detailed in the ESI. $\dagger$ The absorptions around $400 \mathrm{~nm}$ are assigned to localised $\pi-\pi^{*}$ transitions of the phenylene moieties, whereas the absorption at longer wavelengths (around $400 \mathrm{~nm}$ ) are attributed to intramolecular charge-transfer (ICT) absorption bands. ${ }^{\mathbf{4 0 4}}$ The absorption maxima appear at $384 \mathrm{~nm}$ for 6, $404 \mathrm{~nm}$ for 7 and $410 \mathrm{~nm}$ for $\mathbf{8}$, respectively. The moderate red-shift with increased branching indicates relatively weak coupling between successive branches. ${ }^{42}$ A $20 \mathrm{~nm}$ red-shift in $\lambda_{\max }$ between 6 and 7 is indicative of a enlargement of the ICT.$^{43}$ However, as there is only a $6 \mathrm{~nm}$ shift between 7 and 8 this suggests that the addition of a third branch doesn't improve ICT as significantly. ${ }^{20}$ 


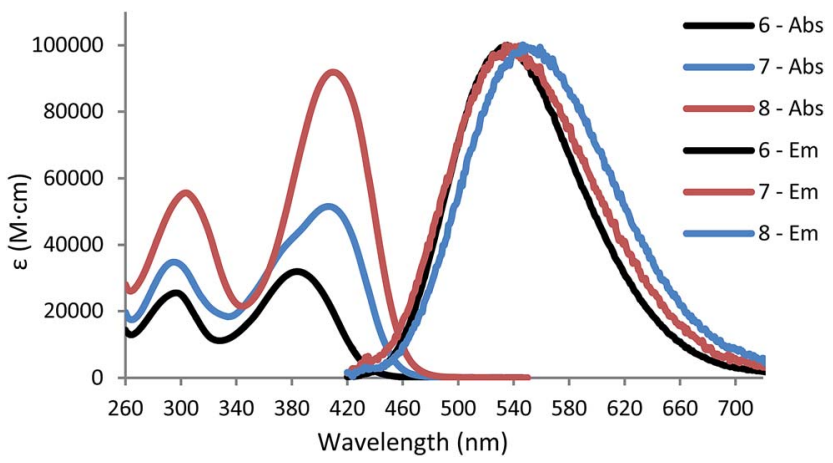

Fig. 1 Normalised UV/Vis absorption spectrum of 6, 7 and 8 in $\mathrm{MeOH}$, concentration of $1 \times 10^{-5} \mathrm{M}$. Normalised fluorescence emission spectrum of 6,7 and 8 in $\mathrm{MeOH}$, concentration of $2 \times 10^{-6} \mathrm{M}$ and excitation at $385 \mathrm{~nm}$.

Table 1 Photophysical properties of $6-8$ in $\mathrm{MeOH}$ and an acrylate mixture $^{a}$

\begin{tabular}{llllllll}
\hline & Solvent & $\lambda_{\max }$ & $\lambda_{\mathrm{Em}}$ & $\varepsilon$ & $\mathrm{ST}$ & $\phi_{\mathrm{F}}$ & $\delta_{2 \mathrm{PA}}$ \\
\hline \multirow{6}{*}{$\mathbf{n}$} & MeOH & 384 & 536 & 3.49 & 152 & 0.198 & 126 \\
& Acrylate & - & 487 & & - & 0.216 & \\
7 & MeOH & 404 & 542 & 5.46 & 138 & 0.021 & 358 \\
& Acrylate & - & 495 & & - & 0.182 & \\
$\mathbf{8}$ & MeOH & 410 & 546 & 9.48 & 126 & 0.019 & 590 \\
& Acrylate & - & 506 & & - & 0.183 &
\end{tabular}

${ }^{a} \lambda_{\max }$ is the one-photon absorption maximum. $\lambda_{\mathrm{Em}}$ is the fluorescence emission maximum, excitation at $385 \mathrm{~nm} . \varepsilon=$ molar extinction coefficient $\left(10^{4} \mathrm{M}^{-1} \mathrm{~cm}^{-1}\right)$ calculated at $\lambda_{\max }$. ST $=$ stokes shift; $\mathrm{ST}=$ $\left(\lambda_{\mathrm{Em}}-\lambda_{\mathrm{Abs}}\right) . \phi_{\mathrm{F}}$ is the fluorescence quantum yield. $\delta_{2 \mathrm{PA}}=$ two-photon absorption as measured at $780 \mathrm{~nm}$ in $\mathrm{CHCl}_{3}$; concentration $2 \times$ $10^{-2}$ M. $1 \mathrm{GM}=1 \times 10^{-50} \mathrm{~cm}^{4} \mathrm{~s}$ per photons per molecule.

The molar extinction coefficients $(\varepsilon)$ at the absorption maxima increase with the number of branches and values of $3.49,5.46$ and $9.48 \times 10^{4} \mathrm{M}^{-1} \mathrm{~cm}^{-1}$ in $\mathrm{MeOH}$ are found for 6, 7 and $\mathbf{8}$, respectively. The fact that the magnitude of the extinction coefficient is approximately proportional to the number of branches suggests relatively independent behaviour of the branches in these PIs. ${ }^{27,42,44}$ However, the $\varepsilon$ for 7 is slightly lower than expected and is likely due to the weak coupling of the two branches. In the absorption spectra for 7 (Fig. 1), a shoulder exists on the high-energy side of the peak resulting from coupling between the branches which splits the excited state into two bands, and are positioned symmetrically with respect to the dipolar species. ${ }^{\mathbf{2 9 , 4 1 , 4 5}}$ This splitting is explained by the Frenkel exciton model, which is also applied to $\mathrm{H}$ - and $\mathrm{J}$ aggregates and assumes electrostatic interaction of the molecules. ${ }^{41,46,47}$ The observed bandwidth broadening of 7 , relative to the absorption of $\mathbf{6}$ and $\mathbf{8}$ further indicates the presence of two split one-photon excited states. ${ }^{27,29}$ This splitting is also predicted to occur in $\mathbf{8}$ with two equivalent excited states being onephoton allowed and the third being two-photon allowed only. The fluorescence emission spectra in $\mathrm{MeOH}$ show a bathochromic shift of the emission band (Fig. 1) and thus suggests the excited state is more polar and therefore, more stabilised by increasing solvent polarity. ${ }^{48}$
This trend can be seen with increasing solvent polarity and more details can be found in the ESI, Fig. S6-S8. $\dagger$

Alongside this bathochromic shift, band broadening was observed with increased solvent polarity and importantly, the emission spectra for $\mathbf{6 , 7}$ and $\mathbf{8}$ are similar; this indicates that excited state emission occurs from a single dipolar branch in all PIs. ${ }^{\mathbf{4 2 , 4 6}}$ This is consistent with previous reports of triphenylamine containing chromophores, where photoexcitation produces an emissive charge-transfer (CT) state that is localised to a single branch..$^{27,29,49-51}$ The large Stokes shifts (ST) that are observed indicate that significant electronic reorganisation takes place after excitation and prior to emission. ${ }^{52}$ The observed ST decreases from 6-8 in $\mathrm{MeOH}$ and this trend is also seen with lower polarity solvents, implying overall excited state polarity decreases with increased branching. The excited state of the dipolar 6 species possesses higher CT character than the respective quadrupolar 7 and octupolar 8 species. ${ }^{45,53}$

Fluorescence quantum yields $\left(\phi_{\mathrm{F}}\right)$ were measured in $\mathrm{MeOH}$ using a known standard (QBS) (Table 1). The $\phi_{\mathrm{F}}$ of the PIs in $\mathrm{MeOH}$ was $19.8 \%, 2.1 \%$ and $1.9 \%$ for 6,7 and 8 , respectively. Increased $\pi$-conjugation and carbonyl acceptor groups are known to reduce overall $\phi_{\mathrm{F}} \cdot{ }^{12}$ Furthermore, from a molecular structure point of view multi-branched species have more tendency to adopt twisted configurations and these consume more energy, thus reducing the overall molecular $\phi_{\mathrm{F}} \cdot{ }^{54}$ This can be rationalised by the effect of phenyl rotation on the CT state. The rotation of the phenyl-N bond on the branches compete to become part of the dipolar CT state and this in turn, reduces the $\phi_{\mathrm{F}} \cdot{ }^{28}$ Moreover, viscosity can play an important role in this process by limiting phenyl-N rotation and its ability to adversely affect fluorescence emission and $\phi_{\mathrm{F}} \cdot{ }^{31,51,55}$ To assess this we measured fluorescence emission and $\phi_{\mathrm{F}}$ in increasingly viscous solvent mediums; including $\mathrm{MeOH}$, ethylene glycol (EG), diethylene glycol (DEG) and the acrylate system we employed for our TPP tests, which consists of a $50: 50 \mathrm{wt} \%$ mixture of SR415 and SR351 (Table S3, ESI $\dagger$ ). SR415 and SR351 are commercially available acrylate monomers and have been previously utilised for TPP tests., ${ }^{3,18}$ The fluorescence emission of 7 and 8 in $\mathrm{MeOH}$ are much smaller than that of $\mathbf{6}$ in the same solvent.

When acrylate is the solvent, however, large increases in fluorescence emission are observed for all three PIs compared to their levels in $\mathrm{MeOH}$ (Fig. 2). The increased local viscosity of the acrylates hinders rotation about the phenyl-N bonds in the branches, and reduces the effectiveness of this conformational dynamics decay pathway relative to the formation of the CT state. Thus the emission spectra of 6-8 in acrylates largely mimic that of the dipolar 6 in $\mathrm{MeOH}$, insofar as the emission is limited to the dipolar branch in all PIs.

To further investigate the excited state behaviour of our compounds, fluorescence lifetime measurements were performed in $\mathrm{MeOH}$ and in our acrylate system (Table 2 and Fig. 3). We observed a bi-exponential decay and calculated weighted average lifetimes for our PIs. ${ }^{56}$ The radiative decay constant $\left(k_{\mathrm{f}}\right)$ and can be calculated using $k_{\mathrm{f}}=\phi_{\mathrm{F}} / \tau$ for 6, 7 and 8. The nonradiative decay constants $\left(k_{\mathrm{nr}}\right)$ can be calculated from $k_{\mathrm{f}}$ and $\phi_{\mathrm{F}}$ according to the following equation: ${ }^{57}$ 


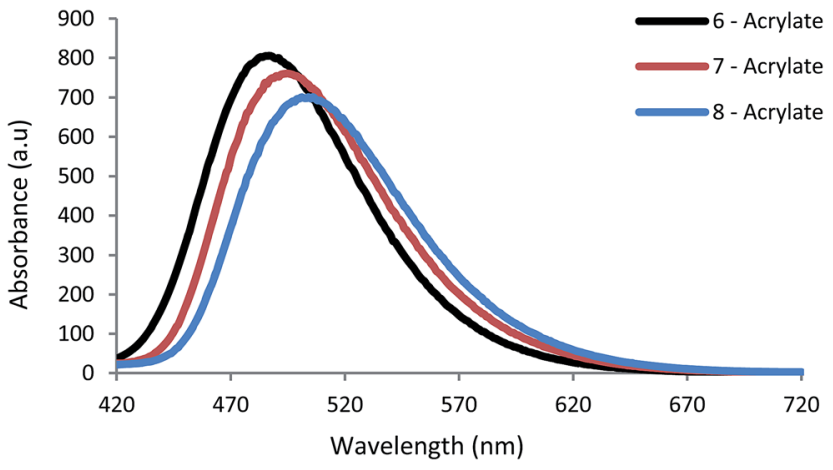

Fig. 2 Fluorescence emission of $6-8$ in acrylate mixture (SR415 : SR351, 50 : $50 \mathrm{wt} \%$ ) with excitation at $385 \mathrm{~nm}$.

Table 2 Fluorescence lifetime, radiative and non-radiative decay constants of PI 6-8

\begin{tabular}{lllll}
\hline & Solvent & $\tau(\mathrm{ns})$ & $k_{\mathrm{f}}$ & $k_{\mathrm{nr}}$ \\
\hline 6 & MeOH & 1.57 & $1.26 \times 10^{8}$ & $5.11 \times 10^{8}$ \\
& Acrylate & 2.08 & $1.04 \times 10^{8}$ & $3.77 \times 10^{8}$ \\
7 & MeOH & 0.55 & $3.82 \times 10^{7}$ & $1.78 \times 10^{9}$ \\
& Acrylate & 2.17 & $8.39 \times 10^{7}$ & $3.77 \times 10^{8}$ \\
8 & MeOH & 0.33 & $5.76 \times 10^{7}$ & $2.97 \times 10^{9}$ \\
& Acrylate & 2.26 & $8.10 \times 10^{7}$ & $3.62 \times 10^{8}$
\end{tabular}

${ }^{a} \tau$ is the fluorescence lifetime in $\mathrm{ns}$ as measured at $375 \mathrm{~nm} . k_{\mathrm{f}}=$ radiative decay constant $\left(\mathrm{s}^{-1}\right)\left(k_{\mathrm{f}}=\phi_{\mathrm{F}} / \tau\right) \cdot k_{\mathrm{nr}}=$ non-radiative decay constant $\left(\mathrm{s}^{-1}\right)$ calculated from eqn (1).

$$
k_{\mathrm{nr}}=\left(\frac{1}{\phi_{\mathrm{F}}}-1\right) k_{\mathrm{f}}
$$

For 6, 7 and 8 in $\mathrm{MeOH}$, lifetimes of $1.57 \mathrm{~ns}, 0.55 \mathrm{~ns}$ and 0.33 ns were measured respectively. The low $\phi_{\mathrm{F}}$ and shorter lifetimes for 7 and 8 can be attributed to the dominant nonradiative decay mechanisms through internal conversion. ${ }^{58}$ In acrylates, the fluorescence lifetimes were $2.08 \mathrm{~ns}, 2.17 \mathrm{~ns}$ and $2.26 \mathrm{~ns}$ for 6, 7 and 8, respectively. The $k_{\mathrm{f}}$ and $k_{\mathrm{nr}}$ values across the series become close to those displayed for $\mathbf{6}$, suggesting that radiative pathways become the dominant process (Table 2). The acrylate viscosity reduces the ability of the branches in 7 and 8 to rotate and disrupt the dipolar CT state evidenced by the similar $k_{\mathrm{nr}}$ values (Table 2). Further evidence of emission being limited to a single dipolar branch, like that observed for 6 can be seen in the similar lifetime decay curves of 6-8 in acrylates (Fig. 3).

\subsection{Two-photon absorption}

The 2PA values were measured using the z-scan technique at $780 \mathrm{~nm}$ in $\mathrm{CHCl}_{3}$ and a sample concentration of $2 \times 10^{-2} \mathrm{M}$. The $\delta_{2 \mathrm{PA}}$ is calculated by open aperture z-scan which can be used to directly obtain the nonlinear absorption coefficient $(\beta)$. When third order nonlinear losses are small, the normalised change in transmittance due to $2 \mathrm{PA}$ can be approximated.$^{59}$ Our results are shown in Table 1 and the normalised data is shown in Fig. 4.

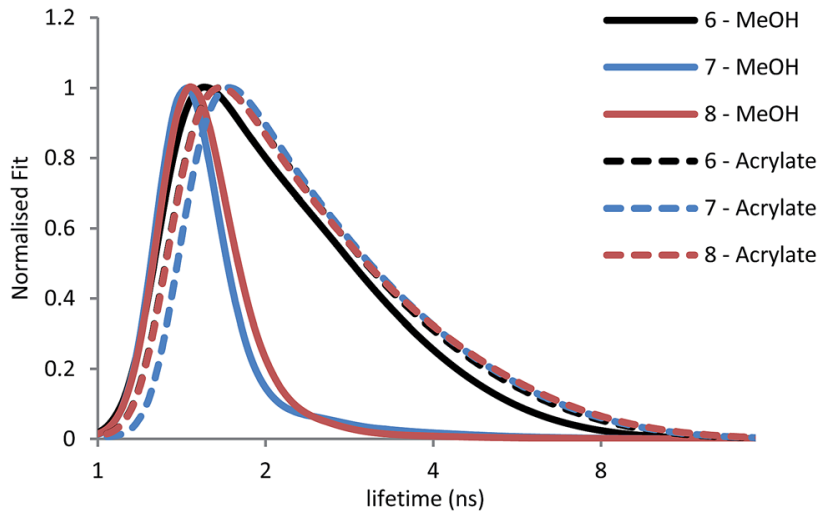

Fig. 3 Fluorescence lifetime decay curves of $6-8$ in $\mathrm{MeOH}$ and acrylates with excitation pulse at $375 \mathrm{~nm}$.

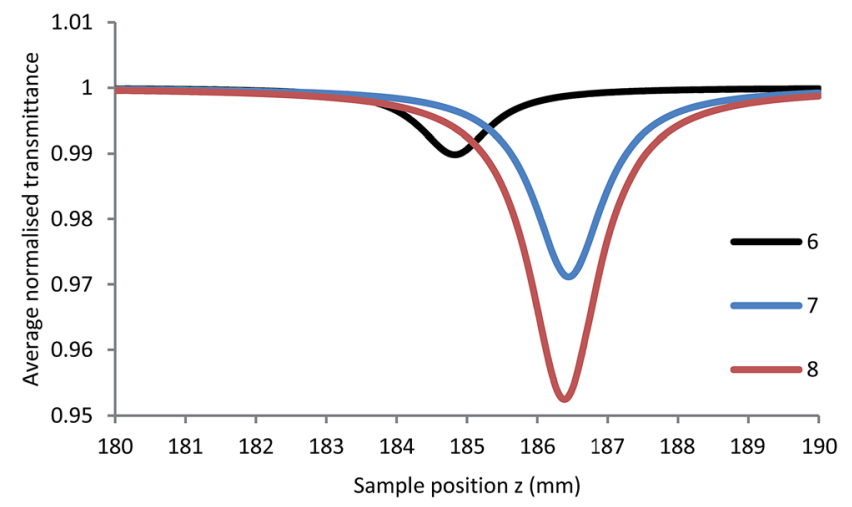

Fig. 4 Normalised z-scan data of $6-8$ in $\mathrm{CHCl}_{3}$ as measured at $780 \mathrm{~nm}$.

$\delta_{2 \mathrm{PA}}$ values of $126 \mathrm{GM}, 358 \mathrm{GM}$ and $590 \mathrm{GM}$ were found for $\mathbf{6}$, 7 and 8 respectively; a linear relationship between $\delta_{2 \mathrm{PA}}$ and the number of branches is seen, with an increase of 232 GM per branch. The branching effect and cooperative enhancement seen in multi-branched triphenylamine core molecules is well reported in the literature. ${ }^{7,8,60}$ With increasing $\pi$-conjugation and the number of acceptors both maximise ICT and thus, $\delta_{2 \mathrm{PA}}{ }^{7}$ The measured one-photon $\lambda_{\max }$ in $\mathrm{CHCl}_{3}$ were $388 \mathrm{~nm}, 411 \mathrm{~nm}$ and $415 \mathrm{~nm}$ for 6,7 and 8, respectively, meaning that the measured GM values are likely to be close to their maximum. However, to obtain a full assessment of the 2PA activity of these molecules, measurements over a broader wavelength range would be necessary as 2PA enhancement is strongly wavelength dependant. ${ }^{27}$ Furthermore, due to the splitting of the excited states predicted by the Frenkel exciton model a broad wavelength would give insights into the 2PA of these higher excited states. Previous studies have shown that for octupolar branches the high-excited state can be blue-shifted with respect to the one-photon maxima. ${ }^{10,27,61}$

\subsection{Two-photon polymerisation}

There exist several methods for evaluating polymerisation efficiency of PIs used in TPP, including laser direct writing of 
single-lines. ${ }^{62}$ More recently, complicated 3D shapes have been fabricated by laser irradiation under a variety of conditions. ${ }^{3,18}$ Here, we evaluated PI efficiency by fabricating a 3D structure consisting of a cross-hatched square (dimensions: $150 \times 150 \times$ $50 \mu \mathrm{m}$, Fig. 5) using $800 \mathrm{~nm}, 110$ femtosecond laser pulses with a variety of pulse energies and write-speeds (total irradiation). A $1: 1$ mixture of SR415 and SR351 (see ESI $\dagger$ ) with a constant PI concentration of $6.3 \times 10^{-6} \mathrm{~mol} \mathrm{~g}^{-1}$ was used, as good results have been obtained using such a formulation previously. ${ }^{3,18} \mathrm{We}$ employed the previously studied PI $E, E-1,4$-bis $\left[4^{\prime}-(N, N\right.$-di- $n$ butylamino)styryl]benzene (R1B) as a reference for our TPP system. It is known to have a $\delta_{2 \mathrm{PA}}$ of $995 \mathrm{GM}$ at $730 \mathrm{~nm}$ and polymerisation threshold of $3.0 \mathrm{~mW} .{ }^{5,63}$ Another study found R1B to polymerise high-quality structures at $12-15 \mu \mathrm{W}$ at $800 \mathrm{~nm}$ and was the basis for our reference system and PI concentration. ${ }^{3,18}$

Our structuring tests found high quality polymerisation thresholds with an average power $(500 \mathrm{~Hz})$ of $36 \mu \mathrm{W}$ with our TPP system, using a concentration of $6.3 \times 10^{-6} \mathrm{~mol} \mathrm{~g}^{-1}$ and writing speed of $50 \mu \mathrm{m} \mathrm{s}^{-1}$. The average laser power employed ranged from 10 to $400 \mu \mathrm{W}$ and writing speeds of $50 \mu \mathrm{m} \mathrm{s}^{-1}, 100$ $\mu \mathrm{m} \mathrm{s}^{-1}, 150 \mu \mathrm{m} \mathrm{s}^{-1}$ and $200 \mu \mathrm{m} \mathrm{s}^{-1}$ were explored. A colour code system as seen in Fig. S13† was used to determine polymerisation thresholds of our PIs at varying writing speeds. Full details of the processing windows, structure quality assignments and polymerisation setup are outlined in the ESI. $\dagger$

In our measurements, we obtained high-quality structures in the low average $\mu \mathrm{W}$ power range for all PIs, at an order of magnitude smaller than many commercial and literature PIs.,26,64-67 Additionally, we observe large high-quality processing windows of 50-100 $\mu \mathrm{W}$ for our PIs (Fig. 6). The PIs 6 and 7 displayed excellent solubility in our chosen monomer system even over a period of $>6$ months. However, over this period 8 began to precipitate out of solution and required stirring and gentle heating to redissolve. Fig. 5 shows the TPP structuring test results at a writing speed of $50 \mu \mathrm{m} \mathrm{s}^{-1}$ and shows the power range required to create high-quality structures.

The colour of each bar represents the qualitative assessment of structure quality of our fabricated structures. For efficient PIs, broad processing windows and low polymerisation thresholds are desired for high throughput manufacturing. ${ }^{67}$ Fabricated structures of the highest quality are in green and possess well defined and smooth walls (Fig. 5). Average quality (orange) contain small imperfections including, holes or overpolymerised filaments originating from the structures. Poor

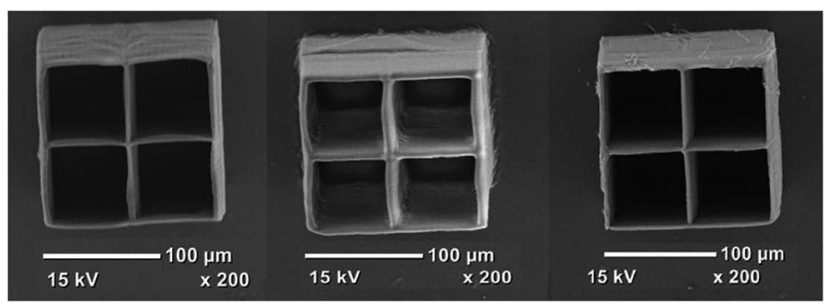

Fig. 5 3D structures showing the generic structure produced by TPP. The structures were fabricated at the minimum 'good quality' polymerisation threshold going from left to right, 6, 7 and 8 were used.

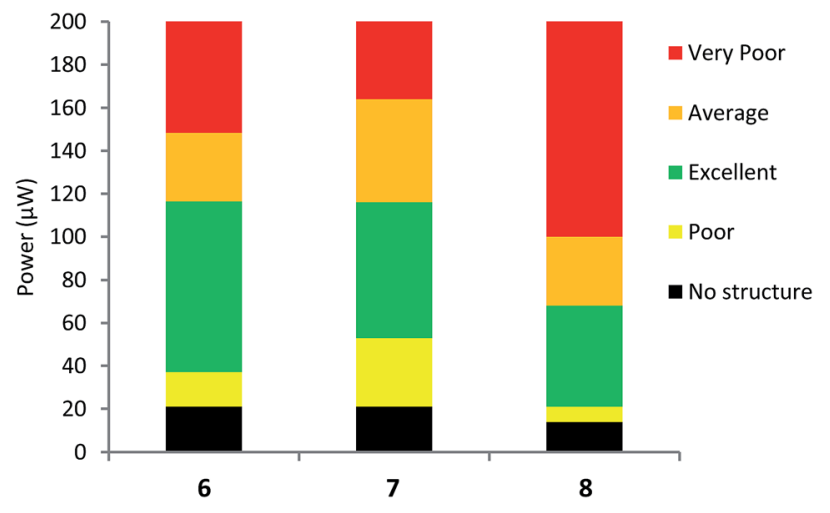

Fig. 6 TPP structuring tests of 6,7 and 8 with writing speed of $50 \mu \mathrm{m}$ $\mathrm{s}^{-1}$. The data above $200 \mu \mathrm{W}$ are omitted here. A full description of our TPP tests at varying writing speeds are detailed fully in the ESI. $\dagger$

quality (yellow) contain major imperfections like collapsed walls and over or under-polymerised features. Finally, very poor quality (red) show very little polymerisation at low power or ablation at high power and the structures barely resemble the desired ones.

At writing speeds of $50 \mu \mathrm{m} \mathrm{s}^{-1}$ we observed good polymerisation thresholds at $27 \mu \mathrm{W}, 45 \mu \mathrm{W}$ and $61 \mu \mathrm{W}$ for 8, 6 and 7, respectively. For 6 , the powers of $45-60 \mu \mathrm{W}$ were seen to polymerise high-quality structures across all the writing speeds and conversely, powers between $80-170 \mu \mathrm{W}$ for the upper limit of the excellent processing window. For 7, a larger minimum power is required for high-quality structures (61-64 $\mu \mathrm{W})$ and a maximum of $122-170 \mu \mathrm{W}$. The octupolar 8 , displayed the lowest polymerisation threshold $(27-36 \mu \mathrm{W})$ and upper limits of 76-108 $\mu \mathrm{W}$ across the writing speeds used.

From our photophysical measurements and $\delta_{2 \mathrm{PA}}$ values, the expected results would be $\mathbf{8}>\mathbf{7}>\mathbf{6}$. However, our TPP results show this isn't the case and in fact, the order is $8>6>7$ for the highest quality structures. The difference in polymerisation thresholds for this series is relatively narrow. As discussed previously, the localised viscosity of the acrylate system adversely affects the overall properties of these PIs, in particular, the $\phi_{\mathrm{F}}$ yields due to limited bond rotation. Consequently, this indicates that while photophysical measurements can suggest the preferred materials for TPP, this does not always translate to the actual structuring tests. These results have important implications for PI design, due to the dipolar nature of the excited state and thus, the origin of initiation. This suggests that synthesising multi-branched PIs to maximise TPP sensitivity may be of limited use.

\section{Conclusions}

We have synthesised a series of multi-branched $\mathrm{D}-\pi-\mathrm{A}_{n}(n=1$, 2 or 3) PIs for use in TPP. We measured large $\delta_{2 \mathrm{PA}}$ up to $590 \mathrm{GM}$ for 8 at $780 \mathrm{~nm}$ and excellent polymerisation thresholds were displayed across the series down to $27 \mu \mathrm{W}$. We showed that due to the dipolar nature of active species in these molecules, viscosity plays a key role in determining their photophysical 
properties like $\phi_{\mathrm{F}}$ yields. This is particularly important for large multi-branched PIs like 7 and $\mathbf{8}$ as branching effects become mitigated. To the best of our knowledge, this is the first report of such effects on TPP thresholds. These results indicate the limited necessity of synthesising large, multi-branched species as a way of maximising polymerisation thresholds for TPP. Consequently, future studies should focus on improvements to structures based on the relatively simple compound $\mathbf{6}$, and could include further extension of conjugation and the incorporation of stronger acceptors to increase the dipolar nature of the molecules.

\section{Acknowledgements}

This work was supported by New Zealand Ministry of Business, Innovation and Employment Grant UOAX1202. Further thanks are also given to those who have contributed to this work including; Reece Oosterbeek, Robert Breukers, the Photon Factory team and members of the Photonics team, Callaghan Innovation.

\section{Notes and references}

1 R. Nazir, E. Balčiūnas, D. Buczyńska, F. Bourquard, D. Kowalska, D. Gray, S. Maćkowski, M. Farsari and D. T. Gryko, Macromolecules, 2015, 48, 2466-2472.

2 Z. Li, M. Siklos, N. Pucher, K. Cicha, A. Ajami, W. Husinsky, A. Rosspeintner, E. Vauthey, G. Gescheidt, J. Stampfl and R. Liska, J. Polym. Sci., Part A: Polym. Chem., 2011, 49, 3688-3699.

3 Z. Li, N. Pucher, K. Cicha, J. Torgersen, S. C. Ligon, A. Ajami, W. Husinsky, A. Rosspeintner, E. Vauthey, S. Naumov, T. Scherzer, J. Stampfl and R. Liska, Macromolecules, 2013, 46, 352-361.

4 R. Nazir, F. Bourquard, E. Balčiūnas, S. Smoleń, D. Gray, N. V. Tkachenko, M. Farsari and D. T. Gryko, ChemPhysChem, 2015, 16, 682-690.

5 Y. Lu, F. Hasegawa, T. Goto, S. Ohkuma, S. Fukuhara, Y. Kawazu, K. Totani, T. Yamashita and T. Watanabe, J. Lumin., 2004, 110, 1-10.

6 B. A. Reinhardt, L. L. Brott, S. J. Clarson, A. G. Dillard, J. C. Bhatt, R. Kannan, L. Yuan, G. S. He and P. N. Prasad, Chem. Mater., 1998, 10, 1863-1874.

7 M. Pawlicki, H. A. Collins, R. G. Denning and H. L. Anderson, Angew. Chem., Int. Ed., 2009, 48, 3244-3266.

8 F. Terenziani, C. Katan, E. Badaeva, S. Tretiak and M. Blanchard-Desce, Adv. Mater., 2008, 20, 4641-4678.

9 Z. Wang, X. Wang, J. Zhao, W. Jiang, P. Yang, X. Fang, M. Zhou and M. Cheng, Dyes Pigm., 2008, 79, 145-152.

10 R. Lartia, C. Allain, G. Bordeau, F. Schmidt, C. FioriniDebuisschert, F. Charra and M.-P. Teulade-Fichou, J. Org. Chem., 2008, 73, 1732-1744.

11 Z. Li, J. Torgersen, A. Ajami, S. Mühleder, X. Qin, W. Husinsky, W. Holnthoner, A. Ovsianikov, J. Stampfl and R. Liska, RSC Adv., 2013, 3, 15939-15946.

12 S. J. Strickler and R. A. Berg, J. Chem. Phys., 1962, 37, 814822.
13 J. Perez-Prieto, R. Galian and M. Miranda, Mini-Rev. Org. Chem., 2006, 3, 117-135.

14 G. Angulo, J. Grilj, E. Vauthey, L. Serrano-Andrés, Ò. RubioPons and P. Jacques, ChemPhysChem, 2010, 11, 480-488.

15 J.-P. Malval, M. Jin, F. Morlet-Savary, H. Chaumeil, A. Defoin, O. Soppera, T. Scheul, M. Bouriau and P. L. Baldeck, Chem. Mater., 2011, 23, 3411-3420.

16 J. Wu, M. Shi, Y. Zhao and F. Wu, Dyes Pigm., 2008, 76, 690695.

17 G. Lemercier, C. Martineau, J.-C. Mulatier, I. Wang, O. Stephan, P. Baldeck and C. Andraud, New J. Chem., 2006, 30, 1606-1613.

18 N. Pucher, A. Rosspeintner, V. Satzinger, V. Schmidt, G. Gescheidt, J. Stampfl and R. Liska, Macromolecules, 2009, 42, 6519-6528.

19 J. Xue, Y. Zhao, F. Wu and D.-C. Fang, J. Phys. Chem. A, 2010, 114, 5171-5179.

20 J. Wu, Y. Zhao, X. Li, M. Shi, F. Wu and X. Fang, New J. Chem., 2006, 30, 1098-1103.

21 R. Nazir, T. T. Meiling, P. J. Cywiński and D. T. Gryko, Asian J. Org. Chem., 2015, 4, 929-935.

22 R. Nazir, P. Danilevicius, A. I. Ciuciu, M. Chatzinikolaidou, D. Gray, L. Flamigni, M. Farsari and D. T. Gryko, Chem. Mater., 2014, 26, 3175-3184.

23 R. Nazir, B. Thorsted, E. Balciunas, L. Mazur, I. Deperasinska, M. Samoc, J. Brewer, M. Farsari and D. T. Gryko, J. Mater. Chem. C, 2016, 4, 167-177.

24 R. Nazir, P. Danilevicius, D. Gray, M. Farsari and D. T. Gryko, Macromolecules, 2013, 46, 7239-7244.

25 X. Wang, F. Jin, W. Zhang, X. Tao, X.-M. Duan and M. Jiang, Dyes Pigm., 2011, 88, 57-64.

26 X. Wang, F. Jin, Z. Chen, S. Liu, X. Wang, X. Duan, X. Tao and M. Jiang, J. Phys. Chem. C, 2011, 115, 776-784.

27 C. Katan, F. Terenziani, O. Mongin, M. H. V. Werts, L. Porrès, T. Pons, J. Mertz, S. Tretiak and M. Blanchard-Desce, J. Phys. Chem. A, 2005, 109, 3024-3037.

28 S. Easwaramoorthi, P. Thamaraiselvi, K. Duraimurugan, A. J. Beneto, A. Siva and B. U. Nair, Chem. Commun., 2014, 50, 6902-6905.

29 D. Cvejn, E. Michail, K. Seintis, M. Klikar, O. Pytela, T. Mikysek, N. Almonasy, M. Ludwig, V. Giannetas, M. Fakis and F. Bures, RSC Adv. , 2016, 6, 12819-12828.

30 B. Dereka, A. Rosspeintner, Z. Li, R. Liska and E. Vauthey, J. Am. Chem. Soc., 2016, 138, 4643-4649.

31 M. A. Haidekker and E. A. Theodorakis, Org. Biomol. Chem., 2007, 5, 1669-1678.

32 K.-S. Lee, K. Ran Hee, Y. Dong-Yol and P. Sang Hu, Prog. Polym. Sci., 2008, 33, 50.

33 A. Sobolev, V. Belsky, I. Romm, N. Y. Chernikova and E. Guryanova, Acta Crystallogr., Sect. C: Cryst. Struct. Commun., 1985, 41, 967-971.

34 A. M. Brouwer, Pure Appl. Chem., 2011, 83, 2213-2228.

35 N. S. Makarov, M. Drobizhev and A. Rebane, Opt. Express, 2008, 16, 4029-4047.

36 P. J. Holliman, M. Mohsen, A. Connell, M. L. Davies, K. AlSalihi, M. B. Pitak, G. J. Tizzard, S. J. Coles, R. W. Harrington, W. Clegg, C. Serpa, O. H. Fontes, 
C. Charbonneau and M. J. Carnie, J. Mater. Chem., 2012, 22, 13318-13327.

37 X. R. B. Gaifa Lai, J. Santos and E. A. Mintz, Synlett, 1997, 1275-1276.

38 T. Mallegol, S. Gmouh, M. A. A. Meziane, M. BlanchardDesce and O. Mongin, Synthesis, 2005, 2005, 1771-1774.

39 D. Ding and G. Yan, Chin. J. Chem., 2012, 30, 1906-1908.

40 D. Beljonne, J. L. Brédas, M. Cha, W. E. Torruellas, G. I. Stegeman, J. W. Hofstraat, W. H. G. Horsthuis and G. R. Möhlmann, J. Chem. Phys., 1995, 103, 7834-7843.

41 L. Yan, X. Chen, Q. He, Y. Wang, X. Wang, Q. Guo, F. Bai, A. Xia, D. Aumiler, S. Vdović and S. Lin, J. Phys. Chem. A, 2012, 116, 8693-8705.

42 F. Terenziani, C. Le Droumaguet, C. Katan, O. Mongin and M. Blanchard-Desce, ChemPhysChem, 2007, 8, 723-734.

43 J. Brunel, O. Mongin, A. Jutand, I. Ledoux, J. Zyss and M. Blanchard-Desce, Chem. Mater., 2003, 15, 4139-4148.

44 C. Liu, K.-C. Tang, H. Zhang, H.-A. Pan, J. Hua, B. Li and P.-T. Chou, J. Phys. Chem. A, 2012, 116, 12339-12348.

45 C. Katan, F. Terenziani, C. L. Droumaguet, O. Mongin, M. H. V. Werts, S. Tretiak and M. Blanchard-Desce, Proc. SPIE-Int. Soc. Opt. Eng., 2005, 5935, 593503.

46 C. Katan, S. Tretiak, M. H. V. Werts, A. J. Bain, R. J. Marsh, N. Leonczek, N. Nicolaou, E. Badaeva, O. Mongin and M. Blanchard-Desce, J. Phys. Chem. B, 2007, 111, 9468-9483. 47 F. Terenziani, C. Sissa and A. Painelli, J. Phys. Chem. B, 2008, 112, 5079-5087.

48 Y. Zhang, M. Jiang, G.-C. Han, K. Zhao, B. Z. Tang and K. S. Wong, J. Phys. Chem. C, 2015, 119, 27630-27638.

49 J. E. Rogers, J. E. Slagle, D. G. McLean, R. L. Sutherland, B. Sankaran, R. Kannan, L.-S. Tan and P. A. Fleitz, J. Phys. Chem. A, 2004, 108, 5514-5520.

50 B. Li, R. Tong, R. Zhu, F. Meng, H. Tian and S. Qian, J. Phys. Chem. B, 2005, 109, 10705-10710.

51 B. Carlotti, E. Benassi, C. G. Fortuna, V. Barone, A. Spalletti and F. Elisei, ChemPhysChem, 2016, 17, 136-146.
52 L. Porrès, C. Katan, O. Mongin, T. Pons, J. Mertz and M. Blanchard-Desce, J. Mol. Struct., 2004, 704, 17-24.

53 G. Ramakrishna and T. Goodson, J. Phys. Chem. A, 2007, 111, 993-1000.

54 X. Wang, P. Yang, G. Xu, W. Jiang and T. Yang, Synth. Met., 2005, 155, 464-473.

55 T. Förster and G. Hoffmann, Z. Phys. Chem., 1971, 75, 63-76.

56 J. R. Lakowicz, Principles of fluorescence spectroscopy, Springer Science \& Business Media, 2013.

57 C. A. Zoto and R. E. Connors, J. Mol. Struct., 2010, 982, 121-126. 58 C. Toro, L. De Boni, S. Yao, K. D. Belfield and F. E. Hernández, J. Phys. Chem. B, 2008, 112, 12185-12190.

59 I. Asselberghs, J. Pérez-Moreno and K. Clays, in Non-Linear Optical Properties of Matter: From Molecules to Condensed Phases, ed. M. G. Papadopoulos, A. J. Sadlej and J. Leszczynski, Springer, Netherlands, Dordrecht, 2006, vol. 14, pp. 419-459, DOI: 10.1007/1-4020-4850-5.

60 G. S. He, L.-S. Tan, Q. Zheng and P. N. Prasad, Chem. Rev., 2008, 108, 1245-1330.

61 M. A. Albota, C. Xu and W. W. Webb, Appl. Opt., 1998, 37, 7352-7356.

62 Y. Ren, X.-Q. Yu, D.-J. Zhang, D. Wang, M.-L. Zhang, G.-B. Xu, X. Zhao, Y.-P. Tian, Z.-S. Shao and M.-H. Jiang, J. Mater. Chem., 2002, 12, 3431-3437.

63 M. Rumi, J. E. Ehrlich, A. A. Heikal, J. W. Perry, S. Barlow, Z. Hu, D. McCord-Maughon, T. C. Parker, H. Röckel, S. Thayumanavan, S. R. Marder, D. Beljonne and J.-L. Brédas, J. Am. Chem. Soc., 2000, 122, 9500-9510.

64 K. D. Belfield, K. J. Schafer, Y. Liu, J. Liu, X. Ren and E. W. V. Stryland, J. Phys. Org. Chem., 2000, 13, 837-849.

65 H.-B. Sun and S. Kawata, in NMR 3D Analysis Photopolymerization, Springer, 2004, pp. 169-273.

66 L. Li and J. T. Fourkas, Mater. Today, 2007, 10, 30-37.

67 C. N. LaFratta, J. T. Fourkas, T. Baldacchini and R. A. Farrer, Angew. Chem., Int. Ed., 2007, 46, 6238-6258. 